\title{
EDUCAÇÃO CONTINUADA: SOLUÇÃO PARA O DESEMPREGO?
}

\author{
VAlÉria De Bettio Mattos* \\ LUCíDIO BIANCHETTI**
}

\begin{abstract}
Não é difícil imaginar o grau de amargura e ressentimento experimentado pelos jovens que permanecem inativos anos e anos a fio, valendo-se de pequenos trabalhos temporários, estágios e outros expedientes, sem garantir seu acesso à sociedade hiperconsumista e, decididamente, impedidos de ter qualquer espécie de autoestima (...). Em suma, mesmo os que exercem algum trabalho não estão isentos por completo da crise da desilusão (...). Aqueles que obtêm diplomas e títulos de pós-graduação estão muito distantes de ascender a cargos condizentes com seus anseios e habilitações (...). Cada vez menos se observa uma ajustada adequação entre o diploma e o nível de emprego. (Gilles Lipovetsky, 2007, p. 22; destaque nosso)
\end{abstract}

\begin{abstract}
RESUMO: Que fatores ajudam a entender o adiamento da inserção de jovens no mundo do trabalho? O que explica recém-graduados continuarem seus estudos em outros cursos (graduação ou pós) ou, ainda, retornarem à universidade? Seria a educação continuada uma saída para o desemprego? Sustentamos que o alongamento da escolarização dos jovens está associado ao estreitamento de oportunidades de trabalho, como apontam Prandi, no Brasil, e Beaud e Pialoux, na França. Discutimos os fenômenos do "engessamento" da mobilidade social, apesar de um grau mais elevado de escolaridade, no caso brasileiro, e o alongamento da escolarização frente ao estreitamento de oportunidades laborais, no caso francês. A análise das trajetórias mostra que o alongamento da escolarização serve como estratégia de enfrentamento ao desemprego e as evidências apontam que não se trata de algo conjuntural, mas sim inerente à própria lógica do capital.
\end{abstract}

Palavras-chave: Trabalho e educação. Desemprego. Alongamento da escolarização.

\footnotetext{
* $\quad$ Doutoranda em Educação pela Universidade Federal de Santa Catarina (UFSC) e professora da Universidade Federal da Fronteira Sul (uffs, Campus Chapecó).E-mail: valeria.mattos@uffs.edu.br

* Doutor em Educação: História, Política, Sociedade e professor no Centro de Ciências da Educação da Universidade Federal de Santa Catarina (UfSC). E-mail: lucidiob@gmail.com
} 


\section{Continuing EDUCATION: A SOLUTION TO UNEMPLOYMENT?}

ABSTRACT: What factors could help us understand why young people enter the job market later and later? Why do high school graduates pursue higher education or others return to university? Would continuing education be a solution to unemployment? Drawing on Prandi in Brazil and Beaud \& Pialoux in France, this paper advocates that this phenomenon is due to decreased job opportunities. It also discusses the "stiffening" of social mobility despite a higher level of education, in Brazil, or longer studies to be better prepared before limited job opportunities, in France. Analyzing some life trajectories shows that longer studies are a strategy to better face unemployment and evidence suggests that they are not a temporary trend but inhere to the very logic of capital.

Key words: Work and education. Unemployment. Scholastic prolongation.

\section{ÉDUCATION CONTINUE: UNE SOLUTION CONTRE LE CHÔMAGE?}

RÉSUMÉ: Quels facteurs permettent de comprendre pourquoi les jeunes entrent de plus en plus tard dans le monde du travail? Qu'est-ce qui explique que des jeunes venant d'obtenir leur bac continuent leurs études (licence ou même master et doctorat) ou encore que d'autres retournent à l'université? L'éducation continue serait-elle une solution au chômage? Nous soutenons que le prolongement de la scolarisation des jeunes est associé à la diminution des occasions de travail, comme l'indiquent Prandi au Brésil et Beaud et Pialoux en France. Nous discutons le phénomène de la "sclérose" de la mobilité sociale malgré un niveau de scolarité plus élevé, dans le cas brésilien, ou le prolongement de la scolarisation pour mieux faire face à la pénurie d'occasions de travails, dans le cas français. L'analyse de trajectoires montre que le prolongement de la scolarisation est une stratégie contre le chômage et tout indique que ce mouvement n'est pas conjoncturel, mais inhérent à la logique même du capital.

Mots-clés: Travail et éducation. Chômage. Prolongement de la scolarisation.

\section{Introdução}

$\mathrm{P}$

or meio do presente texto buscamos compreender as nuanças do trabalho na atualidade, em geral, e, especificamente, as condições da inserção profissional, sobretudo da parcela jovem da população com diploma universitário. A fim de discutir o processo ascendente de precarização no mundo do trabalho, partimos de dados obtidos em pesquisa, com uma amostra de 117 pós-graduandos de diferentes cursos de mestrado, ${ }^{1}$ oferecidos por uma universidade pública do Sul do país.

A amostra foi determinada não a partir de um número previamente estabelecido de indivíduos matriculados em cursos de mestrados oferecidos por essa universidade, mas sim a partir do total de programas de pós-graduação, que à época perfaziam 45. Por meio de um sorteio, buscou-se contemplar $20 \%$ dos cursos nas 
diferentes áreas de conhecimento, a fim de que os dados levantados fossem estatisticamente representativos daquela realidade.

Os dados da pesquisa evidenciam determinadas particularidades, como efeito-demonstração em termos de regionalismo, especificidades do público que o compõe, em relação à condição socioeconômica, idade e gênero, bem como nas relações intergeracionais acerca do grau de instrução e inserção ocupacional/profissional estabelecidas entre os mestrandos pesquisados e as duas gerações precedentes. Embora a pesquisa esteja circunscrita por estas categorias, não será desconsiderada sua universalidade, uma vez que expressam o panorama nacional de um país periférico do sistema capitalista que apresenta manifestações mundiais, como é o caso, por exemplo, da constatação do alongamento da escolarização como estratégia de enfrentamento (ou mascaramento?) dos altos índices de desemprego (Beaud \& Pialoux, 1999) ou das condições precarizadas de trabalho, aqui especificamente relacionadas aos jovens profissionais ${ }^{2}$ (Prandi, 1982), na tentativa de se afirmarem profissionalmente.

A escolha do tema deu-se, sobretudo, pela constatação do número crescente de matrículas nos diversos níveis de pós-graduação (Ribeiro, 2008), ${ }^{3}$ o que nos leva a inferir que o alongamento da escolarização entre os jovens prestes a concluir a graduação ou entre os recém-formados acontece principalmente em razão do estreitamento de oportunidades de trabalho. As diversas justificativas para prosseguir os estudos expressam estratégias individuais adotadas devido à falta de perspectiva frente a um futuro profissional incerto, onde as opções de trabalho/emprego apresentam-se com contornos instáveis e precarizados.

Vale destacar que o processo de alongar a escolarização vem ocorrendo, majoritariamente, às expensas do próprio trabalhador e fora da jornada formal de trabalho. Ressaltamos que esta situação se restringe àqueles que trabalham. Já entre os que não estão trabalhando, a necessidade da continuação dos estudos parece ser um ultimato devido ao processo acirrado de competição por um posto de trabalho, muitas vezes precário, a fim de se tornarem ativos no mercado, que mais exclui força de trabalho do que inclui no padrão de acumulação vigente (Harvey, 1993). Tudo isso se adequa à clássica Teoria do Capital Humano $(\mathrm{Tсн})^{4}$ e, ao mesmo tempo, exige uma releitura acerca do processo de precarização do mundo do trabalho.

Pochmann (2001) ilustra a natureza regressiva e excludente do capital ao mostrar que não há correlação direta entre nível de escolaridade e oportunidade de trabalho. O autor aponta, baseado nos dados da Pesquisa de Emprego e Desemprego (PED/DIEESE-SEADE) da década de 1990, justamente o contrário:

Percebe-se que o desempregado com menor grau de escolaridade apresenta diminuição de sua participação relativa no total do desemprego. Em contrapartida, aqueles que possuem escolaridade mais alta tiveram uma elevação na sua participação no total do 
desemprego (...). Por esse motivo, a educação, embora cada vez mais necessária, não se mostra suficiente para garantir a todos o acesso adequado aos postos de trabalho dos anos 90. (p. 132-133)

Frente a uma realidade limitadora no tocante às oportunidades e às condições de trabalho e a uma ideologia individualista disseminada em todos os âmbitos sociais, o sistema vigente preconiza a obtenção de novas "competências" como medida exclusiva para obter espaço no mundo do trabalho. Dessa forma, buscamos investigar esta parcela elitizada da população, ${ }^{5}$ a fim de obter respostas para as seguintes perguntas: Por que os jovens estão postergando o ingresso no chamado mercado formal de trabalho ou o exercício profissional? Por que há uma tendência dos recém-graduados de continuarem seus estudos em outros cursos de graduação ou na pós-graduação lato e stricto sensu? Por que os que já estão formados retornam à universidade?

\section{Educação continuada em tempos de desemprego}

A тсн "revitalizada" pós-1990 propaga a educação permanente como garantia ou veículo facilitador na obtenção e/ou manutenção de emprego. Apoiados nesta premissa, poderíamos indagar: Seria a educação a salvação para o problema do desemprego e do solapamento da vida social dos trabalhadores? A escolarização alongada possibilitaria a ascensão social? A educação seria a chave para o desenvolvimento socioeconômico de um país?

Se nos baseássemos nas manchetes de jornais, nos discursos cotidianos de políticos ou, ainda, nas plataformas de governo, responderíamos que sim. Entretanto, alguns autores (Hirata, 2002; Castro, 2004; Kuenzer, 2005; Pochmann, 2006; Alves, 2007) fazem críticas a esses discursos que veiculam a ideia da educação como alternativa redentora para todos os males sociais.

É necessário destacar que a educação é apenas a resposta de uma necessidade social, construída historicamente. Portanto, não é boa ou má, suficiente ou insuficiente. Sob as determinantes do modelo de acumulação vigente, talvez possamos afirmar que não temos a educação que gostaríamos, ou melhor, que mereceríamos. Temos, sim, aquela que determinadas condições históricas forjam.

No período medieval, de predominância das corporações, por exemplo, sob o primado das "mãos hábeis", o aprendizado exigia paciência e dedicação para o domínio da técnica, absorvida numa relação específica de mestre-aprendiz. A partir do século XI, nos primórdios da institucionalização da universidade, o trabalho intelectual, personalizado pelos professores, possibilitou a estes ganhar a vida sem ser pelo trabalho das mãos, caracterizando outra relação de mestre-discípulos, na qual o 
trabalho manual se tornou gradativamente prescindível, ao passo que o incentivo ao saber científico se expandiu. Já entre os séculos XVI e xviII, sob o advento do liberalismo contestador, ${ }^{6}$ as propostas educativas emergiram sob a perspectiva de diversos pensadores: Comenius (1592-1670), Locke (1632-1704); Voltaire (1694-1778); Rousseau (1712-1778) e Diderot (1713-1784), entre outros. Ao contestarem os privilégios da aristocracia, propuseram uma educação universalizante.

No século xIx, os liberais conservadores - Tocqueville (1805-1859) e Stuart Mill (1806-1873) - defenderam a ordem capitalista ascendente, contribuindo para um projeto educacional que asseguraria a criação e a recriação de trabalho. Buscaram conservar a ordem do capital, impondo outra racionalidade de cunho pragmático que assentava no plano das ideias a possibilidade de ascensão social.

Nesse sentido, a educação não pode ser entendida como igualitária, democrática e libertadora. Ela é, por excelência, expressão de uma sociedade dividida em classes, cujos contornos e condicionantes se mostram indubitavelmente discriminatórios. E não há, por assim dizer, uma única educação, pois ela não é igual para todos. Embora existam esforços para democratizar a educação e, especificamente aqui, o ensino superior, sustentamos que a educação se manifesta diferentemente, no tempo e no espaço, de acordo com os seus determinantes históricos. Tampouco, o aprendizado ou os aspectos qualificantes dos trabalhadores são os mesmos. A aprendizagem não está suspensa. Ela é historicamente determinada. Como explicita Mészáros (2006, p. 263): “Nenhuma sociedade pode perdurar sem seu sistema próprio de educação".

Decorre daí o entendimento de que somente por meio da apreensão histórica é possível compreender a educação continuada na atualidade e ao mesmo tempo delimitar o nosso objeto de estudo, isto é, a precarização das condições de inserção e manutenção dos trabalhadores no mundo do trabalho.

\section{Desemprego juvenil}

Muitos são os estudos, nas diferentes áreas das ciências sociais e humanas, que buscam compreender o fenômeno do desemprego sob diferentes enfoques. Segundo Pochmann (2002), no ano de 2000 o país ocupou o segundo lugar na hierarquia mundial do desemprego, ${ }^{7}$ sendo que duas décadas antes ocupava a $13^{a}$ posição, fato este que expressa o processo acelerado de produção de miséria e degradação da vida de milhares de brasileiros.

O Brasil ocupa a sexta posição no ranking da economia mundial e concentra a quinta maior população juvenil (36 milhões de jovens entre 15 e 24 anos de idade), entre os quais oito milhões não estudam nem trabalham, ou seja, vivem 
na inatividade. Entre os estudiosos do desemprego juvenil há consenso em apontar uma maior suscetibilidade dos jovens no ingresso e manutenção no mercado de trabalho. Pochmann (1998) indica que em 1997 a taxa de desemprego no segmento da população com idade entre 15 e 24 anos era de 13\%. O autor sustenta que, na década de 1990, paralelamente à escassez de postos de trabalho para os jovens, percebeu-se uma diminuição de ocupação de assalariados e um aumento nos segmentos autônomos, o que evidencia a precarização e instabilidade desse grupo de trabalhadores, diante da desregulamentação do trabalho, e o processo de flexibilização das regras de contratação a que estão submetidos.

Ao mesmo tempo percebemos uma medida preventiva e, em alguns casos, reparatória, adotada individualmente por um número considerável de jovens: prosseguir nos estudos por acreditarem que terão melhores condições de competir por uma vaga no mundo do trabalho e, dessa maneira, evitar o desemprego.

Na nossa pesquisa, partimos da constatação de dois fenômenos concomitantes: o "engessamento" da mobilidade social mediante um grau mais elevado de escolaridade (Prandi, 1982) e o alongamento da escolarização frente ao estreitamento de oportunidades profissionais (Beaud \& Pialoux, 1999). Não pretendemos estabelecer uma relação de causa e efeito. Porém, a partir de nossa investigação, foi possível perceber e discutir as imbricações destes fenômenos ascendentes no mundo ocidental.

\section{O desemprego entre jovens profissionais: os favoritos degradados ${ }^{8}$}

Prandi (1982) revela, por meio de um estudo realizado com universitários paulistanos no início dos anos de 1980, que a disseminação da Teoria do Capital Humano (ТсH) continuava atual, preconizando a titulação universitária como agente facilitador de mobilidade social.

Na sua investigação, verificou que o sonho de ascensão social se mantinha apenas como promessa para a maioria dos titulados, expondo toda a fragilidade deste segmento frente à procura de colocação no mercado de trabalho. $\mathrm{O}$ autor sustenta que, em tempos de altos índices de desemprego, erigido sob a égide da flexibilidade, "uma das funções da universidade é a de manter por mais tempo a população jovem afastada do escasso mercado de trabalho" (p. 79).

Diante da desvalorização do diploma, que guarda correlação, sobretudo, com a queda da qualidade do ensino, assistimos à disseminação de trabalho simples e rotineiro entre os jovens profissionais. Prandi (op. cit.) aponta que, no início dos anos de 1980, menos de um terço da população brasileira diplomada exercia funções que exigiam este nível de escolaridade, um terço exercia funções que outrora exigiriam o nível médio e um quarto dos que possuíam nível médio executava trabalhos manuais. 
Conforme assinala o autor, a partir da década de 1980 é visível o processo de proletarização dos trabalhadores e precarização das condições de trabalho e a busca por assalariamento por parte de todas as categorias profissionais, que, quando possível, trabalham em diferentes locais, a fim de conseguir uma renda mais condizente com suas necessidades de sobrevivência, o que expressa o "engessamento" da sonhada mobilidade social diante de um aumento da escolarização.

Queremos, a partir desta investigação, enfatizar que, na passagem do paradigma que vigorava preponderantemente na produção taylorista-fordista para aquele que passa a ditar a produção toyotista (Harvey, 1993), embora a exigência em termos profissionais sofra uma mudança brusca, demandando profissionais versáteis, polivantes e autônomos, verifica-se, em termos práticos, que esta transição é apenas aparente. A realidade mostra que a grande massa humana produtiva continua a atuar com o seu suporte especialista-funcional.

\section{O alongamento da escolarização face ao estreitamento de oportuni- dades de trabalho}

Hobsbawm (1995) afirma que, junto ao boom do ensino superior na última metade do século xx, desenvolveu-se a esperança de melhoria das condições de vida, mediante o aumento dos níveis de escolaridade, sobretudo para os estratos médios da sociedade, que dependem do seu trabalho para viver. Este apelo era tão forte que os pais não mediam esforços para possibilitar a seus filhos o acesso à universidade:

\footnotetext{
Na verdade, as famílias corriam a pôr os filhos na educação superior sempre que tinham a opção e a oportunidade, porque esta era de longe a melhor chance de conquistar para eles uma renda melhor e, acima de tudo, um status social superior. Dos estudantes latino-americanos entrevistados por pesquisadores em meados da década de $1960 \mathrm{em}$ vários países, entre $79 \%$ e $95 \%$ estavam convencidos de que o estudo os colocaria numa classe social superior dentro de dez anos. (p. 291)
}

Em termos de Brasil, esta tendência encontra eco na realidade. Basta atentarmos ao fato de que, na atualidade, praticamente em quase toda família brasileira há um estudante universitário. ${ }^{9}$ No entanto, esta outra tendência se concretiza em um mundo do trabalho com desqualificação nos processos laborais, nos quais as tarefas simplificadas parecem predominar.

Apoiados na teoria desenvolvida por Beaud e Pialoux (1999) sobre o alongamento da escolarização como alternativa ao desemprego iminente e ao esfacelamento das condições de trabalho e do movimento sindical entre os operários franceses da Peugeot, traçamos um paralelo da educação alongada no Brasil e na França, a fim de discutir suas aproximações e limitações. ${ }^{10}$ Se na França o estudo relacionou três 
gerações de trabalhadores oriundos de regiões operárias e os respectivos percursos ocupacionais/profissionais, aqui a discussão se deu com base na análise da trajetória profissional intergeracional, entre os mestrandos, seus pais e avós, diante do estreitamento de oportunidades no mundo do trabalho.

Os autores apresentam a tese da negação da condição operária, ao identificarem que os filhos dos operários vão à universidade, na época do boom do ensino superior na França; mas os filhos de seus filhos, isto é, a terceira geração, mediante o estreitamento de oportunidades de trabalho, visível a partir dos anos de 1980, não consegue fazer o mesmo. O que se apresenta então é um novo contexto: o neto sequer consegue ser operário, não tendo outra alternativa senão o desemprego. $O$ depoimento de um jovem operário de 27 anos ilustra a hipótese por eles aventada: “(...) ter um pai que trabalha na linha de produção era vergonhoso... era a vergonha de trabalhar no chão da fábrica. Agora é um pouco menos, porque, hoje em dia, ter um serviço já é bom, independentemente de ser no chão da fábrica ou não" ${ }^{11}$ (Beaud \& Pialoux, op. cit., p. 324).

Os autores concluem que, embora o alongamento da escolarização seja uma realidade, esta tendência não fornece garantias quanto ao futuro profissional. Pelo contrário, o que se torna notório é o estreitamento das oportunidades. Se a geração anterior, com nível escolar inferior ao de seus filhos, conseguia manter um padrão de vida aceitável, o mesmo não acontece próximo da virada do milênio com os filhos, portadores de diplomas profissionalizantes e até universitários.

Neste sentido, mediante a instabilidade do trabalho nas diversas formas manifestas, o alongamento de escolaridade caracteriza-se como uma das estratégias mais contundentes de enfrentar o desemprego. Pochmann (1998) demonstra que este fenômeno cresce mundialmente, ao exemplificar, por intermédio de dados franceses, que em 1974 a média era de 15 anos e seis meses de estudo e, duas décadas mais tarde, em 1996, passou a ser de 18 anos e quatro meses.

Depreendemos daí que, especialmente em relação à população jovem, prevalece o alongamento da escolarização como forma de "protegê-la" da inatividade profissional. O objetivo do empresariado é claro: investir em formação profissional com vistas a aumentar a produtividade, a qualidade e a competitividade no mercado. ${ }^{12}$ Já para os trabalhadores, na batalha pela sobrevivência, os objetivos se tornam menos nítidos diante das possibilidades de formação profissional. ${ }^{13}$

Em termos de realidade nacional, os dados do Departamento Intersindical de Estatística e Estudos Socioeconômicos (DIEESE, 2004) ${ }^{14}$ mostram que, neste ano, a população jovem (entre 16 e 24 anos) somava 6,5 milhões de pessoas e representava 46,5\% do total de desempregados na Pesquisa Emprego e Desemprego (PED), tendência que se mantém até os dias atuais. 


\section{Resultados da pesquisa}

Levando em consideração o dado apontado anteriormente, a tese do alongamento da escolarização ganha força, tendo em vista o estreitamento de oportunidades de trabalho para cerca de $54 \%$ dos mestrandos participantes da pesquisa, que afirmaram não estar trabalhando. ${ }^{15}$ Em relação à população investigada, por ser majoritariamente jovem (80\% têm até 30 anos), acreditamos que os dados do Gráfico 1 reforçam a hipótese de estreitamento de oportunidades, na medida em que, após certo tempo decorrido da graduação, os profissionais retornam à universidade, a fim de estender a escolarização diante dos altos índices de desemprego e das condições cada vez mais frágeis de inserção e manutenção no mundo do trabalho.

\section{Gráfico 1}

Distribuição dos mestrandos pesquisados segundo o tempo decorrido entre o término da graduação e o ingresso no mestrado ${ }^{16}$

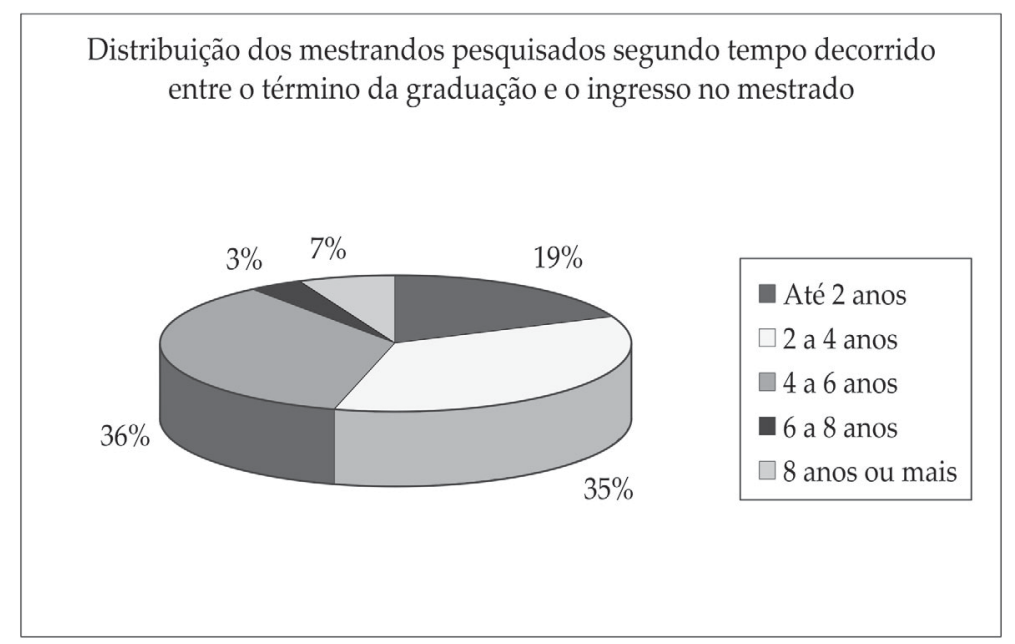

Os dois segmentos com maior incidência (entre 2 e 6 anos) somados perfazem $71 \%$ dos pesquisados, o que corrobora a ideia do alongamento da escolaridade como estratégia para obter melhores condições de trabalho. Mas, por outro lado, reforça a tese de estreitamento das oportunidades profissionais, o que nos leva a aventar a hipótese de que estas pessoas já buscaram inserção ou reinserção no chamado mercado de trabalho e que, por não terem encontrado opções condizentes com suas expectativas ou, ainda, por estarem em situação de desemprego, retornaram à universidade como forma de ganhar tempo, adquirir experiência, desenvolver "competências", entre tantos outros jargões elencados pelos jovens que não encontram 
trabalho. E, de mais a mais, não consideramos nesta análise $14 \%$ dos participantes que afirmaram nunca ter trabalhado, aspecto que corrobora a ideia de alongamento da escolarização, mas não os coloca na situação de desemprego, uma vez que nunca estiveram empregados.

Outro dado importante diz respeito a $62 \%$ dos pesquisados que não recebem bolsa de estudo, índice superior ao de desocupados (54\%) e que externaliza ainda mais a precarização das condições desta população, tendo em vista que teriam direito ao benefício, já que não possuem vínculo empregatício. Além disso, $47 \%$ têm renda domiciliar de até $R \$ 2.000,00$ /mês e $16 \%$ afirmam exercer algum tipo de atividade não regulamentada (informal), dados que escancaram o processo de esfacelamento das condições materiais de um grupo, considerado privilegiado.

Mesmo quando analisamos a natureza do trabalho entre os $46 \%$ que trabalham, a precarização da vida social persiste, uma vez que apenas $35 \%$ deles desenvolvem alguma atividade laboral regulamentada, como demonstra o gráfico a seguir:

\section{Gráfico 2}

Distribuição dos estudantes pesquisados que trabalham por condição de emprego

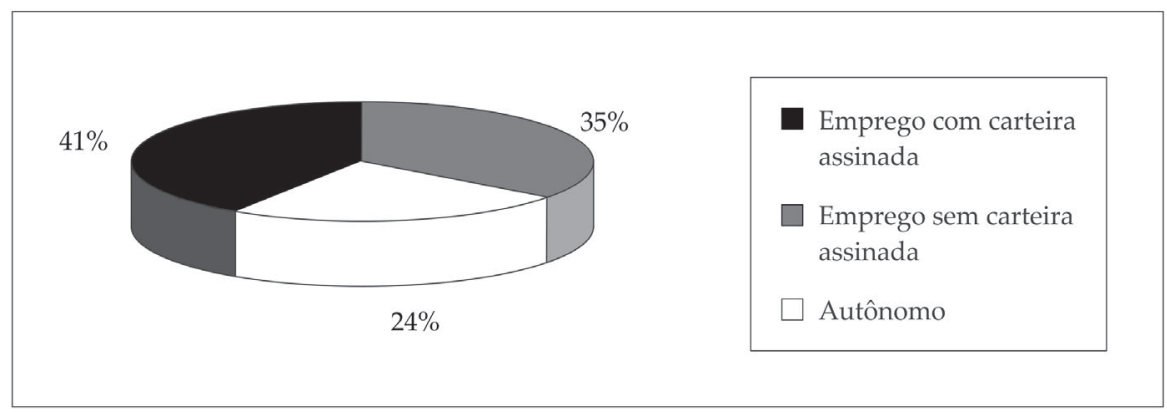

A fim de aprofundar a compreensão sobre o fenômeno do desemprego e do processo de precarização a que os jovens estão submetidos, investigamos o nível de escolarização dos pais e avós, bem como a natureza das atividades laborais que exercem/exerceram, objetivando fazer uma análise da diminuição de oportunidades de inserção/manutenção no mercado de trabalho e dos problemas decorrentes desta situação.

Inicialmente, em relação ao gênero feminino, os dados de nossa pesquisa reforçam a prevalência de mulheres com níveis mais elevados de escolarização, inclusive perpassando gerações, no caso de nossa amostra, de maioria feminina, cujas 
mães apresentam graus de escolaridade diversos, mas que contemplam proporções importantes nos níveis mais altos de escolarização.

A partir dos dados referentes à escolarização das mães e da realidade dos jovens pesquisados, podemos traçar um paralelo com a tese de Beaud e Pialoux (1999). Quando analisamos a progressão educacional e profissional entre as três gerações pesquisadas, percebemos um mesmo percurso: as avós, em sua maioria, não foram à universidade (apenas $5 \%$ delas possuem/possuíram um diploma). Já as suas filhas, numa proporção significativa (37\%), frequentaram um curso superior. E mesmo aquelas que não tiveram acesso à universidade desenvolvem/desenvolveram alguma atividade ocupacional. Já a terceira geração, a que compõe a população pesquisada, alonga ainda mais seus estudos, quando comparada à escolaridade das mães, mas não encontra as mesmas oportunidades no mundo do trabalho, uma vez que $54 \%$ dos pesquisados não trabalham.

Já em relação à trajetória ocupacional/profissional dos avôs paternos e pais dos nossos pesquisados, os dados mostram que os primeiros, em sua maioria (62\%), exerceram ou ainda exercem ocupações que prescindem de titulação universitária, sendo que somente $8 \%$ conquistaram um diploma, sem considerar a porcentagem expressiva (30\%), a qual não foi possível avaliar, uma vez que os pesquisados não informaram a resposta solicitada. No entanto, a ausência de um diploma universitário não os impediu de propiciar aos seus filhos, os pais de nossos pesquisados, o acesso à universidade, cuja maior incidência em relação ao grau de escolaridade dos pais se deu na categoria "superior completo" (25\%), seguida pelas categorias "médio completo" (21\%), "fundamental completo" e "pós-graduação", ambas com a mesma representatividade (18\%).

Tal disparidade nestes últimos números nos levou a relacioná-los com as profissões citadas nos questionários, as quais nos remetem à ruptura entre o espaço rural e urbano, bem como às condições socioeconômicas das famílias. Há um número considerável de registros de pais agricultores, com grau de escolaridade inferior ao dos seus genitores, cujos pais - avôs da amostra - eram fazendeiros e, embora provenientes de um mesmo meio rural, tiveram condições de morar em cidades em que havia ensino superior, concluíram um curso universitário e, inclusive, em alguns casos, cursaram uma pós-graduação.

A distribuição variada entre as diferentes categorias descritas nos levou a verificar a correlação entre o grau de escolaridade e a profissão/ocupação dos pais dos pesquisados, onde a maior prevalência ( $54 \%$ ) se deu na categoria "ocupação sem titulação universitária", conforme expressa o Gráfico 3.

A partir destes dados, pareceu-nos importante analisar as ocupações/profissões dos pais dos nossos investigados, a fim de verificar as especificidades do tipo de 
trabalho desenvolvido e sua relação com o grau de escolaridade, bem como investigar a predominância de titulação universitária em cursos considerados elitizados, em detrimento de outros, cuja procura e status são menos visíveis.

\section{Gráfico 3}

Distribuição dos estudantes pesquisados segundo profissão/ocupação do pai

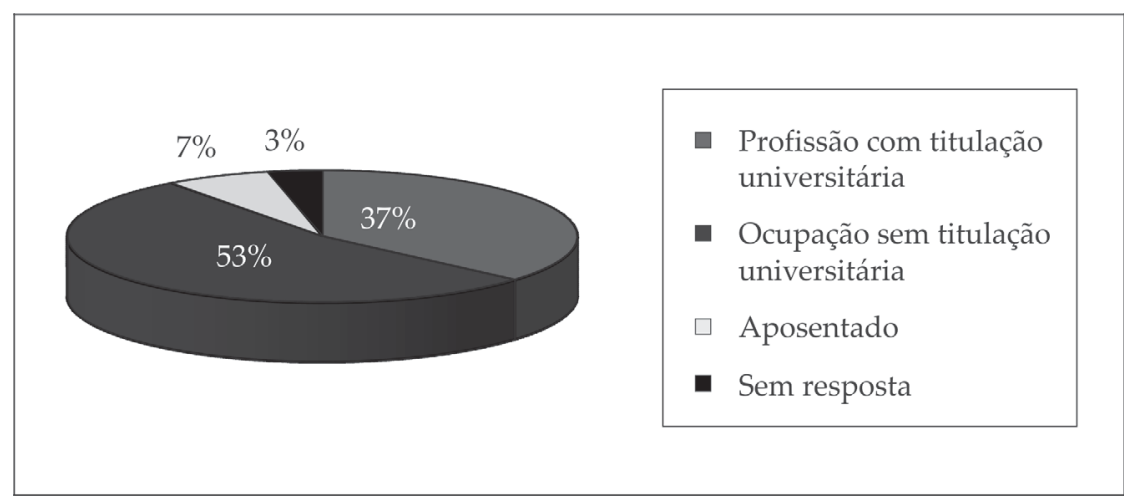

Conforme indica o Gráfico 4, nos cursos de Odontologia e Engenharia Ambiental, $58 \%$ e $60 \%$ dos pais, respectivamente, possuem formação universitária. Nos cursos de Economia e Sociologia Política, embora não prevaleçam profissões (certificadas por uma instituição do ensino superior), há um número significativo de profissionais, cujos índices alcançam $40 \%$ e $42 \%$, nesta ordem.

\section{Gráfico 4}

Distribuição dos mestrandos por cursos pesquisados de acordo com profissão/ocupação do pai

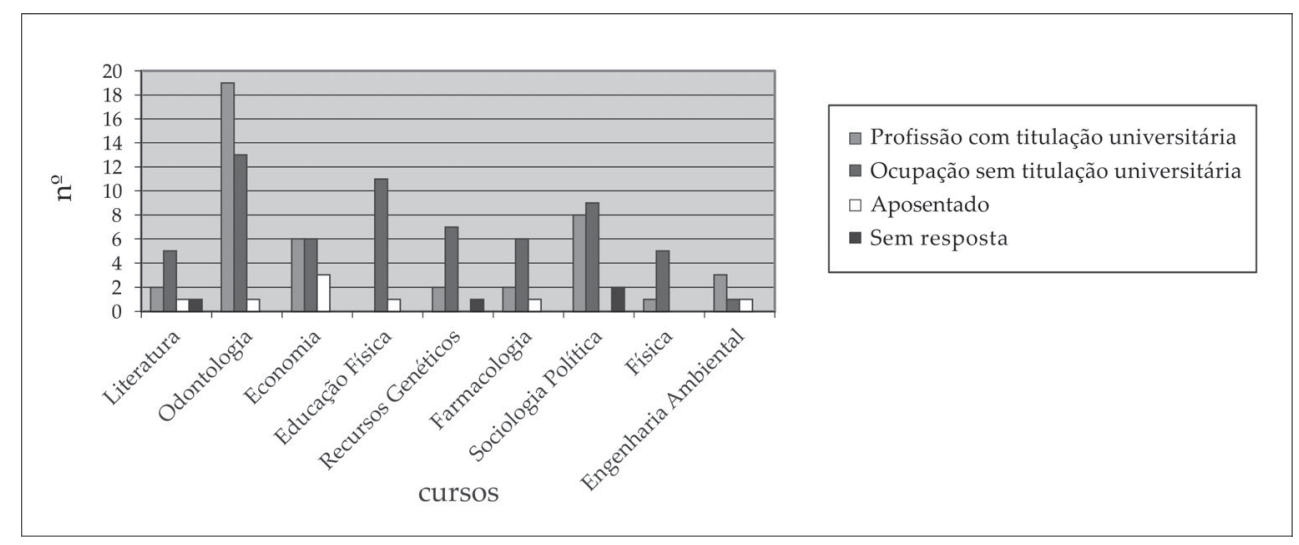


Prevalecem em todos os demais cursos, com exceção de Odontologia e Engenharia Ambiental, conforme citamos, atividades do tipo ocupação, as quais prescindem de titulação universitária. Além disso, apenas no curso de Educação Física nenhum pai possui ou exerce uma profissão, considerações estas que, de algum modo, reforçam o senso comum, no que tange aos aspectos socioeconômicos e ao status proveniente do tipo de formação educacional e profissional das famílias da amostra investigada.

Embora a relação entre origem social e trajetória escolar/profissional não tenha sido melhor investigada na nossa pesquisa, é possível depreender destes dados que, salvo poucas exceções, o pertencimento a um mesmo estrato social se mantém. A tendência de dar continuidade à sua origem socioeconômica persiste, como afirmam Charlot e Glasman (1999, p. 16): “De qualquer forma, as ligações permanecem fortes entre o espaço familiar, a escola e o mundo do trabalho."

Por se tratar de um segmento elitizado, uma vez que os investigados não apenas conseguiram ter acesso ao ensino superior, como avançaram, a partir do ingresso na pós-graduação, percebemos a necessidade de confirmar esse "privilégio" no percurso educacional anterior. Para tanto, verificamos a natureza das instituições nas quais estudaram majoritariamente durante seu percurso educacional, desde o ensino fundamental até o ensino superior. Concluímos destes dados que o circuito virtuoso, de acordo com Romanelli (2003, p. 103-4), se mantém, ou seja, "o estudante frequenta o ensino fundamental e médio em escolas particulares e universidade pública; no circuito vicioso, o aluno percorre trajetória inversa", uma vez que prevaleceu, no âmbito privado, a escolarização nos níveis fundamental (46\%) e médio (59\%) e, no âmbito público, o ensino superior (72\%).

\section{Considerações finais}

A produção abundante e descartável de mercadorias, num sistema que reduz, gradativamente, o seu tempo de vida útil, aponta para a prescindibilidade dos trabalhadores, face à impossibilidade de sobrevivência caso não vendam sua força de trabalho. E, ao mesmo tempo, põe em xeque a continuidade do capital, cuja forma precípua de se reproduzir se dá por meio da exploração do trabalho vivo. Prevalece o padrão de acumulação capitalista e com ele a obsolescência programada das mercadorias (inclusive da força de trabalho), a degradação das condições laborais e, consequentemente, a subsunção real da vida social ao capital (Mészáros, 2002).

Os dados da pesquisa sugerem que as formas de precarização coexistem com o desemprego e a informalização, pois, mesmo entre os estudantes de pós-graduação que trabalham, $65 \%$ exercem atividades laborais sem vínculo empregatício. 
Entendemos que estes índices são reveladores do tamanho do desemprego entre os jovens profissionais.

Ressaltamos a característica endógena do desemprego à relação social capitalista. As explicações que o consideram ora circunstancial, ora estrutural, não levam em conta o seu caráter social e histórico. Nesse sentido, seria redundante entendêlo como estrutural, dado que compõe a estrutura excludente do capital. Embora saibamos que a base empírica não expressa a totalidade dos alunos da instituição pesquisada, ela subsidia a compreensão de que a solução do desemprego não depende apenas de voluntarismo ou de modismos. $\mathrm{O}$ fenômeno do desemprego e da precarização ascendente, visível no mundo do trabalho, é fato e compõe a estrutura do capital.

A investigação mostra uma dissonância entre o grau de escolarização dos trabalhadores e o nível de complexidade do trabalho que desenvolvem ou que tentam desenvolver. A realidade objetiva nos leva a desmistificar a educação como solução para problemas sociais, tais como o desemprego, além de colocar em xeque a bandeira levantada desde o século xIx pelos liberais conservadores, de que a educação caracteriza a principal arma para promover a ascensão social, "solução" que não encontra respaldo na realidade, conforme evidenciam os dados da pesquisa. É um equívoco atribuir à educação a solução de problemas históricos, uma vez que estes decorrem das relações sociais estabelecidas em épocas específicas (Fiod, 1999).

Salientamos ainda que a busca de aprofundamento teórico-prático profissional é uma questão histórica e reflete, portanto, determinadas necessidades sociais. Assim, é possível inferir que, enquanto estivermos sob o primado do capital, o desemprego e a precarização da vida social, independentemente das medidas reparatórias do Estado e do grau de escolarização da população, persistirão. Conforme lembra Alves (2007, p. 8),

(...) a mundialização do capital impõe uma lógica de exclusão social que limita a capacidade do sistema de produção de mercadorias integrar indivíduos numa vida produtiva. É um limite estrutural intrínseco à nova forma de acumulação capitalista. Mesmo que todos pudessem adquirir as novas qualificações, o sistema orgânico do capital seria incapaz de absorvê-los. O mercado não é para todos.

Por fim, entendemos que o alongamento da escolarização dos mestrandos pesquisados em relação às gerações precedentes, embora se constitua como estratégia para enfrentar o desemprego, não propicia garantias sobre o futuro profissional, no que concerne à natureza do posto de trabalho, nem tampouco a inserção e manutenção no mundo do trabalho. Esta, contudo, é uma questão que está sendo privilegiada no processo de continuidade da pesquisa. 


\section{Notas}

1. Os cursos selecionados foram: Sociologia Política, Educação Física, Física, Farmacologia, Odontologia, Engenharia Ambiental, Economia, Literatura e Recursos Genéticos Vegetais.

2. Conforme Aued (2003, p.16), desde a segunda metade do século xx, o termo profissional nos remete diretamente à titulação universitária "que permite acesso a um mercado de trabalho profissional que, no limite, é fechado".

3. Em coletânea que reúne artigos de autores de diversos países e continentes, o ex-diretor de avaliação da CAPES, Renato Janine Ribeiro, faz-se presente com um relato das potencialidades e dos limites remanescentes, no processo de implementação da pós-graduação no Brasil em um contexto, como se explicita no título da obra, de esforços e de iniciativas Toward a Global PhD. A questão da forte expansão das matrículas em todas as áreas figura com destaque no texto do autor.

4. Como veremos logo adiante, a situação atual demanda uma revisita a essa teoria, uma vez que estamos diante de situações novas, as quais exigem que falemos em neoteoria do cH, tendo em vista que a tese central da correlação das variáveis "elevação da escolarização" = "elevação da renda" não encontra mais respaldo na materialidade. Como lembra Gentili (2005), a partir da década de 1970, a promessa da escola como entidade que garantiria a integração social no sentido amplo está em xeque.

5. Reforçamos a noção de que o segmento da população que tem acesso à universidade é elitizado, uma vez que o Censo de Educação, realizado pelo IBGE em 2003, apontou que apenas 3,43\% da população havia concluído um curso de nível superior. A média da escolaridade da população brasileira (6,1 anos) está muito aquém do exigido para a obtenção de um diploma universitário, conforme explicitam os dados do IBGE (2004). De outra parte, ao tratar da questão da elite, é interessante que se tenha presente a pesquisa coordenada por Catani (2007), a respeito da relação "riqueza e desigualdade", onde as estratégias da elite estão sendo investigadas.

6. O liberalismo é definido como um sistema de ideias (ideologia) elaborado pelos pensadores franceses e ingleses no contexto de luta de classes da burguesia contra a aristocracia. No século xviII, essa ideia se corporificou na bandeira revolucionária francesa da classe burguesa aliada momentaneamente aos trabalhadores (Cunha, 1981).

7. De acordo com dados da Organização das Nações Unidas (ONU) daquele ano, a primeira posição era ocupada pela Colômbia.

8. Título do livro de Prandi (1982) em alusão ao exército de reserva intelectual, constantemente refeito por jovens profissionais que, quando não estão desempregados, encontram-se desempenhando funções para as quais sua titulação é prescindível.

9. Não estamos contradizendo o caráter elitista da universidade, evidenciado na nossa pesquisa. Queremos enfatizar o esforço das famílias dos estratos socioeconômicos médios e baixos da sociedade de possibilitar a seus filhos o acesso à universidade, por acreditar que o diploma lhes propiciará um futuro melhor, no que diz respeito a melhores oportunidades de trabalho. Contudo, lembramos que muitas vezes, por falta de condições financeiras até para subsidiar o transporte e a alimentação do estudante, a continuidade dos estudos no ensino superior é interrompida; basta atentarmos para os índices de evasão do ensino superior, sobretudo nas instituições privadas, para as quais estão direcionadas em sua maioria as políticas públicas de incentivo desenvolvidas pelo governo, como é o caso do ProunI, para ficarmos em apenas um dos exemplos da "intransparência" (Habermas, 1987) entre o público e o privado.

10. Salientamos que, embora existam semelhanças entre as realidades brasileira e francesa no que tange à precariedade da vida social, elas não podem ser comparadas de maneira direta, já que dizem respeito a situações distintas em termos históricos, político-sociais, desenvolvimentistas e culturais. Ainda que estejam sob um mesmo padrão de acumulação, cada país guarda as suas particularidades, de acordo com a sua história e o projeto expansionista que favorece mais ou menos a expropriação dos direitos de seus cidadãos. De mais a mais, cabe aqui a metáfora marxiana de que o mais avançado contém e explica o mais atrasado. 
11. Tradução do francês realizada pelos autores.

12. Segundo Maarek (citado por Canals e Sandrine, 1995), a produtividade a partir do trabalho executado por trabalhadores qualificados aumenta em torno de $30 \%$, quando comparado aos não qualificados.

13. Franco (1999, p. 107) esclarece que o próprio sentido da palavra qualificação se torna uma generalização abstrata, "onde o seu significado não se deduz de uma aplicação semântica, mas do conjunto de mediações que se estabelecem nas relações econômico-sociais, tecnológicas e organizacionais que envolvem os processos de trabalho (...) em transformação, cujos contornos não são sempre claros porque têm atrás de si os interesses dos diferentes sujeitos sociais".

14. Dados obtidos no jornal Brasil de Fato (www.brasildefato.com.br), acessado em 19 set. 2005.

15. Poderíamos aventar a possibilidade do não recebimento de bolsas pela maioria dos mestrandos, por se tratar de trabalhadores que estudam e que não teriam, portanto, direito ao benefício concedido pelos órgãos governamentais, conforme a legislação em vigor na época. No entanto, o índice de não bolsistas (62\%) é superior ao número de não trabalhadores, fato este que pode sugerir uma condição socioeconômica familiar que permite auxiliar o parente que estuda, ou uma situação precarizada na tentativa de aliar estudo nas horas de não trabalho, o que configura o perfil do trabalhador-estudante.

16. A pesquisa dos autores subsidiou os dados apresentados nos gráficos que seguem.

\section{Referências}

ALVES, G. Dimensões da reestruturação produtiva: ensaios de sociologia do trabalho. 2. ed. Londrina: Práxis, 2007. Disponível em: <www.giovannialves.org/Capitulo\%2010_ texto.pdf>

AUED, B.W. Indicações metodológicas ao estudo das profissões no Brasil. In: CONGRESSO BRASILEIRO DE SOCIOLOGIA, 11., 2003, Campinas. Anais... Campinas: UNICAMP, 2003. p. 81.

BEAUD, S.; PIALOUX, M. Retour sur la condition ouvrière: enquête aux usines Peugeot de Sochaux-Montbéliard. Paris: Fayard, 1999.

CANALS, V.; SANDRINE, M. La formation-insertion: vers une nouvelle forme d'emploi? Sciences de la Modernité, Paris, n. 36, p. 112-117, oct. 1995.

CASTRO, R.C. Escola e mercado: a escola face à institucionalização do desemprego e da precariedade na sociedade colocada ao serviço da economia. Perspectiva, Florianópolis, v. 22, n. 1, p. 79-92, jan./jun. 2004.

CATTANI, A.D. A escolarização das classes abastadas. Sociologias, Porto Alegre, v. 9, n. 18, p. 170-187, jun./dez. 2007.

CHARLOT, B.; GLASMAN, D. Les jeunes, l'insertion, l'emploi. 2. ed. Lille: Puf, 1999.

CHAUÍ, M. A universidade pública sob nova perspectiva. Revista Brasileira de Educação, Rio de Janeiro; Campinas, n. 24, p. 6-14, set./dez. 2003. 
CUNHA, L.A. Educação e desenvolvimento social no Brasil. 6. ed. Rio de Janeiro: Francisco Alves, 1981.

DUARTE, N. As pedagogias do aprender a aprender: algumas ilusões da assim chamada sociedade do conhecimento. Revista Brasileira de Educação, Rio de Janeiro; Campinas, n. 18, p. 35-40, set./dez. 2001.

FIOD, E.G.M. A educação do molusco que vira homem. In: Aued, B.W. (Org.). Educação para o (des)emprego. Petrópolis: Vozes, 1999. p. 83-108.

FRANCO, M.C. Formação profissional para o trabalho incerto: um estudo comparativo Brasil, México e Itália. In: FrigotTo, G. (Org.). Educação e crise do trabalho: perspectivas de final de século. 3. ed. Petrópolis: Vozes, 1999. p. 100-137.

FRIGOTTO, G. Educação e crise do capitalismo real. 3. ed. São Paulo: Cortez, 1999.

FRIGOTTO, G. (Org.). Educação e crise do trabalho: perspectivas de final de século. 3. ed. Petrópolis: Vozes, 2002.

GENTILI, P. Três teses sobre a relação trabalho e educação em tempos neoliberais. In: Lombardi, J.C. et al. (Org.). Capitalismo, trabalho e educação. 3.ed. Campinas: Autores Associados; HISTEDRB, 2005. p. 45-60.

HABERMAS, J. A nova intransparência: a crise do Estado de bem-estar social e o esgotamento das energias utópicas. Novos Estudos CEBRAP, São Paulo, n. 18, p. 103114, set. 1987.

HARVEY, D. Condição pós-moderna. São Paulo: Loyola, 1993.

HIRATA, H. Da polarização das qualificações ao modelo das competências. In: FERRETTI, C. J. et al. (Org.). Novas tecnologias, trabalho e educação: um debate multidisciplinar. 8. ed. Petrópolis: Vozes, 2002. p. 124-144.

HOBSBAWM, E. A era dos extremos: o breve século xx: 1914-1991. São Paulo: Cia das Letras, 1995.

KUENZER, A.Z. Exclusão includente e inclusão excludente: a nova forma de dualidade estrutural que objetiva as novas relações entre educação e trabalho. In: LoMbardi, J.C.; Saviani, D.; Sanfelice, J.L. (Org.). Capitalismo, trabalho e educação. 3. ed. Campinas: Autores Associados; HISTEDrb, 2005. p. 77-96.

LE GOFF, J. Le trois vagues de la formation permanente. In: Pennec, S. Former des adultes: 1'université et les transformations de 1'emploi. Rennes: Les Pur Presses Universitaries, 2002. p. 101-120.

LIPOVETSKY, G. A sociedade da decepção. Barueri: Manole, 2007. 
MÉSZÁROS, I. Para além do capital. São Paulo: Boitempo; Campinas: UnICAMP, 2002. MÉSZÁROS, I. A teoria da alienação em Marx. São Paulo: Boitempo, 2006.

POCHMANN, M. Inserção ocupacional e o emprego dos jovens. São Paulo: Associação Brasileira de Estudos do Trabalho, 1998.

POCHMANN, M. A metrópole do trabalho. São Paulo: Brasiliense, 2001.

POCHMANN, M. E-Trabalho. São Paulo: Publisher Brasil, 2002.

POCHMANN, M. Crianças e adolescentes e o mundo do trabalho. Trabalho apresentado no Encontro da Região Sul “Trabalho Infantil: violação de direitos humanos" realizado pelo Fórum Estadual de Erradicação do Trabalho Infantil e Proteção ao Adolescente no Trabalho de Santa Catarina em parceria com o Fórum Nacional. Florianópolis, 17 a 18 de agosto de 2006.

PRANDI, J.R. Os favoritos degradados. São Paulo: Loyola, 1982.

RIBEIRO, R.J. Doctoral education in Africa, South America and México: Brazil. In: Nerad, M.; Heggelund, M. (Ed.). Toward a global PhD?: forces and forms in doctoral education worldwide. Seattle: University of Washington, 2008.

ROMANELLI, G. Famílias de camadas médias e escolarização superior dos filhos: o estudante trabalhador. In: Nogueira, M.A. et al. (Org.). Família e escola: trajetória de escolarização em camadas médias e populares. Petrópolis: Vozes, 2003. p. 99-124.

Recebido em 17 de dezembro de 2009.

Aprovado em 23 de fevereiro de 2011. 